\title{
The effect of AIDS defining conditions on immunological recovery among patients initiating antiretroviral therapy at Joint Clinical Research Centre, Uganda
}

\author{
Brian K Kigozi*1, Samwel Sumba ${ }^{1}$, Peter Mudyope ${ }^{1}$, Betty Namuddu ${ }^{1}$, \\ Joan Kalyango ${ }^{1}$, Charles Karamagi ${ }^{1}$, Mathew Odere ${ }^{2}$, Elly Katabira ${ }^{3}$, \\ Peter Mugyenyi ${ }^{2}$ and Francis Ssali ${ }^{2}$
}

Address: ${ }^{1}$ Clinical Epidemiology Unit, Faculty of Medicine, Makerere University College of Health Sciences, P.O. BOX 7072, Kampala, Uganda, ${ }^{2}$ Joint Clinical Research Centre, P.O. BOX 10005, Kampala, Uganda and ${ }^{3}$ Faculty of Medicine, Makerere University College of Health Sciences, P.O. BOX 7072, Kampala, Uganda

Email: Brian K Kigozi* - bkigozi@med.mak.ac.ug; Samwel Sumba - samyamjam@yahoo.com; Peter Mudyope - mudyopek@yahoo.com; Betty Namuddu - kitattab@yahoo.com; Joan Kalyango - nakayaga2001@yahoo.com; Charles Karamagi - karamagi2000@yahoo.com; Mathew Odere - modere@jcrc.co.ug; Elly Katabira - katabira@imul.com; Peter Mugyenyi - pmugyenyi@jcrc.co.ug; Francis Ssali - franSsali@jcrc.co.ug

* Corresponding author

Published: 24 July 2009

AIDS Research and Therapy 2009, 6:17 doi:10.1186/1742-6405-6-17
Received: 9 February 2009

Accepted: 24 July 2009

This article is available from: http://www.aidsrestherapy.com/content/6/I/I7

(C) 2009 Kigozi et al; licensee BioMed Central Ltd.

This is an Open Access article distributed under the terms of the Creative Commons Attribution License (http://creativecommons.org/licenses/by/2.0), which permits unrestricted use, distribution, and reproduction in any medium, provided the original work is properly cited.

\begin{abstract}
Background: Many HIV-infected patients only access health care once they have developed advanced symptomatic disease resulting from AIDS Defining Conditions (ADCs). We carried out a study to establish the effect of $A D C s$ on immunological recovery among patients initiated on antiretroviral therapy (ART).

Methods: A retrospective cohort of 427 HIV-I patients who were initiated on ART between January 2002 and December 2006 was studied. Data on ADCs was retrieved from Joint Clinical Research Centre (JCRC) data base and backed up by chart reviews. We employed Kaplan-Meier survival curves to estimate median time to $50 \mathrm{CD} 4$ cells $/ \mu$ from the baseline value to indicate a good immunological recovery process. Cox proportional hazard models were used at multivariate analysis.

Results: The median time to gaining $50 \mathrm{CD} 4$ cells/ $\mu \mathrm{l}$ from the baseline value after ART initiation was longer in the ADC (9.3 months) compared to the non-ADC group (6.9 months) (log rank test, $p=0.027$ ). At multivariate analysis after adjusting for age, sex, baseline CD4 count, baseline HIV viral load, total lymphocyte count and adherence level, factors that shortened the median time to immunological recovery after ART initiation were belonging to the non-ADC group ( $H R=1.31 ; 95 \% \mathrm{Cl}: 1.03-1.28, p=0.028)$, adherence to ART of $\geq 95 \%(\mathrm{HR}=2.22 ; 95 \% \mathrm{Cl}: \mathrm{I} .57-3.15, \mathrm{p}=0.00 \mathrm{I})$ and a total lymphocyte count $\geq$ 1200 cells $/ \mathrm{mm}^{3}$ (HR $\left.=1.84 ; 95 \% \mathrm{Cl}: \mathrm{I} .22-2.78, \mathrm{p}=0.003\right)$. A low baseline CD4 count of $\leq 200 \mathrm{cells} / \mu \mathrm{l}(\mathrm{HR}$ $=0.52 ; 95 \% \mathrm{Cl}: 0.37-0.77, p=0.00 \mathrm{I}$ ) was associated with a longer time to immunological recovery. There was no interaction between low CD4 counts and ADC group.
\end{abstract}

Conclusion: Patients with ADCs take longer to regain their CD4 counts due to the defect in the immune system. This may prolong their risk of morbidity and mortality. 


\section{Introduction}

During 2005, the World Health Organization (WHO) had estimated that there were over 1.3 million people receiving anti retroviral therapy (ART) in low and middleincome countries, representing $20 \%$ of 6.5 million estimated to need it [1]. In Uganda, the estimated number of patients on ART is over 135,000 out of 300,000 patients in dire need of treatment and for the past 6 years its use has markedly expanded as part of the ART scale-up that started in 2003 with 30,000 patients[2,3].

As the number of individuals able to access treatment is increasing, one of the challenges facing ART services in sub-Saharan Africa is that many HIV-infected patients only access healthcare once they have developed advanced symptomatic disease resulting from AIDS Defining Conditions (ADCs)[4]. The median CD4 cell count among those enrolling in ART programmes is often very low, which increases morbidity and mortality $[4,5]$. Advanced pre-treatment immunodeficiency has also been found to be associated with diminished capacity for restoration of CD4 cell counts and CD4 cell functional responses after ART initiation. Therefore, this raises the concern that many ADCs patients entering ART programmes in sub-Saharan Africa may have limited potential for immunological recovery[5,6]. This problem is further compounded by the fact that the number of studies on people with ADCs and immunological recovery are being limited. In this paper we examine the effect of ADCs on immunologic recovery among naive patients initiated on ART at Joint Clinical Research Centre (JCRC), Kampala, Uganda.

\section{Methods \\ Study design and patient selection}

This study was a retrospective cohort. JCRC is one of the established centers providing ART and is located in Kampala, the capital city of Uganda. It was founded in 1991 and has been providing anti-retroviral therapy since 1996 . Combination ART (CART) became available in 1998 but was quite expensive at that time. Generic Fixed Drug cART which was much cheaper(about $\$ 50 /$ month) and more accessible by 2002 under the UNAIDS/Ministry of Health (Uganda) HIV Drug Access Initiative Programme [7]. We retrieved data from JCRC data base of all patients who had been initiated on ART between 2002 and 2006. This was backed up by chart review for all charts queried from the data base. During the period the study was done, the data beyond December 2006 was not yet available in the JCRC data set. The patients were $\geq 18$ years and ART naive. The exposure of interest was the presence of ADCs at ART initiation among these patients. We classified ADCs according to the WHO clinical staging system [8]. A patient was classified as belonging to the ADC group if was diagnosed with an ADC in the period 12 weeks before or 12 weeks after ART initiation. This classification excludes patients with tuberculosis infections who were on intensive phase of anti-tuberculosis treatment due to the drug interactions and poor virological response [9]. We also excluded patients seen at baseline that had no subsequent followup and patients who had previous exposure to dual ART due to poor virological response [10]. The study was approved by the Makerere University College of Health Sciences Research and Ethics Committee. The primary end point was time from ART initiation to immunological recovery, which was defined as the attainment of $\geq 50$ $\mathrm{CD} 4$ counts/ $\mu \mathrm{l}$ above the baseline CD4 cell count that indicated a good immunological recovery process $[11,12]$.

\section{Diagnostic methods}

Diagnosis was done and documented in the charts by the attending physician. This depended on history from the patient, clinical examination, and backed up by laboratory results. HIV wasting syndrome was defined as more than $10 \%$ documented loss of body weight and either unexplained chronic diarrhea (> one month), or chronic weakness and unexplained prolonged fever (> one month) with pyrexia recorded on at least on one occasion [8]. Cryptosporidiosis was diagnosed by modified Ziehl Nielsen stain on faecal smear; cryptococcal infection was diagnosed on Indian ink stain of cerebral spinal fluid; muco-cutaneous herpes simplex infection and oesophageal candidiasis were diagnosed clinically; tuberculosis infections were diagnosed by presence of acid fast bacilli from lymph node biopsy, or a pleural effusion with a lymphocytosis which responded to anti-tuberculosis treatment. Kaposi sarcoma was diagnosed histologically, although some cases were diagnosed clinically. Cerebral Toxoplasmosis depended on a positive computer tomography scan, and or a focal neurological disease with a high titre of Ig $\mathrm{G}$ antibodies.

\section{Laboratory assessment}

Laboratory measurements included a complete blood cell count, CD4 lymphocyte count, and quantitative measurement of HIV load. Quality control assurance was done in reference to international accredited laboratories; UK National External Quality Assessment Service (UKNEQAS) and College of American Pathologists (CAP).

Viral load count was done with use of Amplicor monitor standard assay, version 1.5 (Roche Molecular Systems), with a minimum detection limit of 400 copies $/ \mathrm{ml}$. In 2006, an assay with a detection limit of 50 copies/ml was acquired by the unit. Viral load count was not consistently done.

CD4 lymphocytes were analyzed by flow cytometry (Bendict Dickson, USA). This was periodically done every 6 
months during the routine visit to the out-patient clinic. Frequently, this schedule was not routinely followed and depended upon the discretion of the attending physician during the interim visits when patients were sick. The time to immunological recovery was estimated to the nearest clinic visit and CD4 count. We right censored patients if they were lost to follow-up after a period exceeding 12 weeks or when failed to gain 50 CD4 cells/ $\mu$ l above the baseline value. A patient was considered lost to follow-up if did not make contact with JCRC out-patient clinic for a period exceeding 90 days during the study period. Adherence to ART was determined according to the patient's previous four days recall when visited the JCRC outpatient clinic and was considered when the patient took $\geq$ $95 \%$ of the prescribed medications [13].

\section{Statistical analysis}

We aimed to achieve a sample size with a power of $90 \%$ to detect the differences between ADC and non-ADC group, and was estimated using formula for survival analysis [14]. We set the level of statistical significance, $\alpha$ at 0.05. The data was queried in MS ACCESS, exported to MS EXCEL and analyzed using STATA (version 8). KaplanMeier survival curves were used to estimate median time to immunological recovery. Cox regression hazard models were used to determine factors influencing time to immunological recovery. We fitted a Cox regression models that included all variables which were statistically significant at bivariate analysis. Sex was included in the models because of the previous findings from a study [15]. The interaction between baseline CD4 count and other variables (group status, age, sex, total lymphocyte count, adherence level and viral load) was assessed by performing a Chunk test. At baseline CD4 count of 50, 100, $150,200,250$ and 350 cells/ $\mu l$, we compared the -log likelihood of the model with interaction terms to a model without the interaction terms. Interaction was considered when the difference (multiplied by 2) of the -log likelihood was greater than the critical chi-square value of 12.59 at 6 degrees of freedom.

\section{Results}

We queried 609 patients from data base who were initiated on antiretroviral therapy between January $1^{\text {st }} 2002$ and December $31^{\text {st }} 2006$, at JCRC out-patient clinic. This number excludes patients who are currently enrolled in ongoing clinical trials and patients who were monitored by physicians outside the JCRC facility but receiving ART at JCRC pharmacy, whose data is stored else where. A total of 182 records were excluded because the patients were seen once at ART initiation and lacked follow-up visits or had previous exposure to dual ART. The remaining 427 patients whose records were used for analysis, had baseline CD4 load count and had been seen on one or more subsequent visits within a period of 12 months follow-up
(Figure 1). Out of 413 patients who had a baseline viral load assay, $213(51.2 \%)$ had a second or subsequent viral assay. Sixty nine percent $(148 / 213)$ achieved a detection limit of 400 or less copies/ml during the first year of ART. Among the patients that achieved viral suppression to a detection limit of 400 or less copies/ml, 68.2\% (101/148) belonged to the non-ADC group.

\section{Descriptive analysis}

Of 427 patients who were initiated on ART, 32.3\% belonged to the ADC group. The most prevalent ADCs were tuberculosis infections, HIV wasting syndrome, Kaposi sarcoma, pneumocystis jerovici pneumonia and cerebral toxoplasmosis (Table 1). The baseline characteristics of 427 patients initiated on ART were comparable in the ADC and non-ADC groups (patients who did not have ADCs at ART initiation), with exception of CD4 counts, adherence level, WHO stage and weight (Table 2). During the follow-up, the mean number of consultations by the patients (due to any infectious cause) at the out-patient clinic in the ADC group was higher than that of the nonADC group, $16(\mathrm{SD}=8.5)$ vs $7(\mathrm{SD}=4.8), \mathrm{p}=0.020$.

\section{Bivariate analysis of socio-demographic and clinical factors}

We studied 427 patients who contributed a total of 123,094 patient-days of follow-up. Three hundred and twenty $(74.9 \%)$ patients attained immunological recovery during the study period, giving an overall immunological recovery rate of 2.5 per 1000 patient-days. The proportions of patients achieving immunological recovery were $13.0 \%$ (18/138), 39.9\% (55/138), 56.5\% (78/138), $71.7 \%(99 / 138)$ in the ADC group at $3,6,9$ and 12 months respectively. For the non-ADC group, the proportion of patients achieving immunological recovery were $13.1 \%$ (38/289), 40.8\% (118/289), 64.0\% (185/289), $77.2 \%(223 / 289)$ at $3,6,9$ and 12 months respectively. The median time to immunological recovery in the ADC group was longer than that of the non-ADC group (271 vs 208 days), (logrank test, $\mathrm{p}=0.019$ ) (Figure 2).

Old age ( $>40$ years), having no ADC at ART initiation, a baseline total lymphocyte count of $\geq 1200$ cells $/ \mathrm{mm}^{3}$ and adherence to ART $(\geq 95 \%)$ were associated with reduced time to attain immunological recovery. A low baseline CD4 count $(\leq 200$ cells $/ \mu \mathrm{l})$ and a high viral load count $(\geq$ $6.0 \log$ copies $/ \mathrm{ml}$ ) were associated with a longer time to attain immunological recovery (Table 3 ).

\section{Multivariate analysis}

The time to attain immunological recovery decreased among patients with no ADCs, a total lymphocyte count of $\geq 1200$ cells $/ \mathrm{mm}^{3}$ and those with adherence to ART was equal or greater than 95\%. A low baseline CD4 count of $\leq$ 200 cells/ $\mu$ l at ART initiation was associated with a longer 


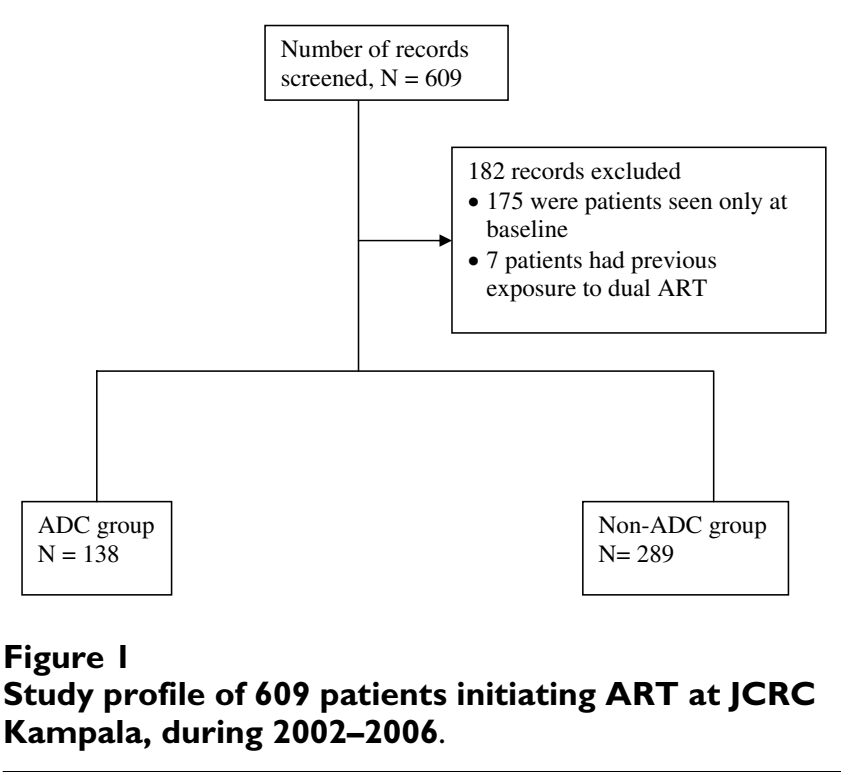

time to immunological recovery (Table 4). There was no interaction between the baseline CD4 counts and other variables (group status, age, sex, baseline viral load, baseline total lymphocytes) at 50, 100, 150, 200, 250 and 350 cells $/ \mu \mathrm{l}$.

\section{Discussion}

In our study we found that the median time to immunological recovery after ART initiation was 271 days (9.3 months) in the ADC group compared to 208 days (6.9 months) in the non-ADC group. The ADC group status was associated with a longer median time to immunological recovery after ART initiation in comparison to the non-ADC group. Factors that were independently associated with time to immunological recovery were group status (presence or absence of ADC), baseline CD4 count, baseline total lymphocyte count and adherence to ART. Although, immunological responses to ART have been

Table I: ADC diagnoses among 138 patients initiated on ART at JCRC during 2002-2006

\begin{tabular}{lll}
\hline $\begin{array}{l}\text { ADC Diagnoses } \\
\text { N = I96 }\end{array}$ & Frequency & Percentage \\
\hline Tuberculosis infections & & \\
HIV wasting syndrome & 63 & 32.1 \\
Kaposi sarcoma & 51 & 26.0 \\
Pnuemocystis jerovici pneumonia & 21 & 10.7 \\
Toxoplasmosis & 17 & 8.7 \\
Cryptococcal meningitis & 15 & 7.7 \\
Esophageal candidiasis & 12 & 6.1 \\
$*$ Others & 10 & 5.1 \\
& 7 & 3.6 \\
\hline
\end{tabular}

* 2 CMV retinitis, 2 HSV mucocutaneous infection > I month, I lymphoma, I cryptosporidial diarrhea, I MAC infection estimated to be at least an increase of 50-100 CD4 cells/ $\mu \mathrm{l} /$ year after ART initiation, the median time to attain this CD4 cell threshold has not been documented $[12,16]$. We took the worst case scenario and estimated a gain of at least $50 \mathrm{CD} 4 \mathrm{cells} / \mu \mathrm{l} /$ year from the baseline value to indicate good immunological recovery process.

The differences in median times to immunological recovery between the ADC and non-ADC group found in our study may be a result of profound pre-treatment immunosuppression which is a common feature of ADCs. The ADCs cause a loss of CD4 memory cells that represent a component of the T-cell repertoire that is specific to most ADC infections. The defect in the CD4 memory cells as a result of ADCs accounts for the inability of patients with ADCs to respond to recall antigens and evoke immunological responses leading to a slower immunological recovery process compared to patients without ADCs [17]. Another explanation could be that the presence of ADCs causes immune activation that leads to increased infection of CD4 cells by HIV virus. This leads into CD4 cell destruction and increased viral replication [18]. Our findings seem to support these findings and are similar to other studies in a multi-centre clinical trial where patients with ADCs who were followed-up for 144 weeks who had a slower immunological recovery than patients without ADCs [19]. The contrasting feature of this study from our study is that it did not determine the median time to immunological recovery. We found that the hazard of attaining immunological recovery when a patient had no ADC increased by 1.3 times compared to when a patient had an ADC.

Other determinants that favored a good immunological recovery process after ART initiation were a baseline CD4 count ( $>200$ cells $/ \mu \mathrm{l}$ ), baseline total lymphocytes count $\left(\geq 1200\right.$ cells $/ \mathrm{mm}^{3}$ ) and adherence to ART $(\geq 95 \%)$. The hazard of attaining immunological recovery reduced when comparing a patient with $\leq 200 \mathrm{CD} 4$ cells/ $\mu$ lo a patient with $>200$ cells $/ \mu$ l by $50 \%$. Our results are consistent with other studies where immunological recovery is largely dependent on baseline CD4 count and thus the timing of ART initiation is important in order to maximize the CD4+ T-cell response to therapy [19]. In contrast, one study from South African community cohort that followed-up patients for 44 weeks, found that patients who had a baseline CD 4 count below or equal to 50 cells $/ \mu l$ had equivalent or greater immunological recovery compared to patients with higher baseline CD4 count [16]. We found out that there was no interaction between CD4 count and other variables (group status, viral load count, total lymphocyte count, age, sex), although it has been documented else where $[20,21]$. The lack of interaction may be a result of inadequate power due to limited sample size among the various CD4 count strata. 
Table 2: Baseline comparison of socio-demographic and clinical characteristics of 427 patients initiated on ART at JCRC, during 20022006

\begin{tabular}{|c|c|c|c|}
\hline Variables & $\begin{array}{l}\text { ADC group } \\
N=138\end{array}$ & $\begin{array}{l}\text { Non-ADC group } \\
N=289\end{array}$ & p-value \\
\hline \multicolumn{4}{|l|}{$\operatorname{Sex}(\%)$} \\
\hline Male & $59(42.8)$ & $103(35.3)$ & 0.137 \\
\hline Female & $79(57.2)$ & $187(64.7)$ & \\
\hline \multicolumn{4}{|l|}{ Age (years) } \\
\hline Mean (SD) & $40(11)$ & $40(10)$ & 0.331 \\
\hline \multicolumn{4}{|l|}{ Occupation (\%)* } \\
\hline Salaried & $36(27.1)$ & $105(37.5)$ & 0.185 \\
\hline Non-salaried & $55(41.4)$ & 106(37.9) & \\
\hline Peasant & $6(4.5)$ & II(3.9) & \\
\hline Unemployed & $36(27.1)$ & $58(20.7)$ & \\
\hline \multicolumn{4}{|l|}{ Education (\%)* } \\
\hline None & $24(17.8)$ & $54(19.1)$ & 0.380 \\
\hline Primary & $51(37.8)$ & $88(30.9)$ & \\
\hline Post-Primary & $60(44.4)$ & $142(50.0)$ & \\
\hline \multicolumn{4}{|l|}{ Residence by district (\%)* } \\
\hline Inside Kampala & $78(58.7)$ & $136(5 \mid .5)$ & 0.178 \\
\hline Outside Kampala & $55(41.4)$ & $128(48.5)$ & \\
\hline \multicolumn{4}{|l|}{ Marital status (\%)* } \\
\hline Married & $57(42.5)$ & $105(38.8)$ & 0.818 \\
\hline Single & $40(29.9)$ & $88(32.5)$ & \\
\hline Widowed & $23(17.2)$ & $53(19.6)$ & \\
\hline Separated/divorced & $14(10.5)$ & $25(9.1)$ & \\
\hline \multicolumn{4}{|l|}{ CD4 (cells $/ \mu l)$} \\
\hline Median (IQR) & $74(28,75)$ & $147(64,240)$ & 0.001 \\
\hline \multicolumn{4}{|l|}{ Viral load (copies log $10 / \mathrm{ml}$ ) } \\
\hline Median (IQR) & $6.8(6.0,12.1)$ & $6.0(6.0,11.6)$ & 0.256 \\
\hline \multicolumn{4}{|l|}{$\mathrm{TLC}^{+}\left(\right.$cells $\left./ \mathrm{mm}^{3}\right) \times 10^{3}$} \\
\hline Median (IQR) & $1.8(1.3,2.6)$ & $1.9(1.3,2.6)$ & 0.409 \\
\hline \multicolumn{4}{|l|}{ Hemoglobin (g/dl) } \\
\hline Median (IQR) & $11.6(10.4,13.5)$ & $12.1(10.4,13.5)$ & 0.277 \\
\hline \multicolumn{4}{|l|}{ Adherence (\%)* } \\
\hline Median (IQR) & $60(0,100)^{\mathrm{a}}$ & $95(20,100)^{b}$ & 0.001 \\
\hline \multicolumn{4}{|l|}{ WHO stage (\%) } \\
\hline I & $0(0)$ & $15(6.6)$ & 0.001 \\
\hline 2 & $0(0)$ & $105(46.3)$ & \\
\hline 3 & $0(0)$ & 107(47.1) & \\
\hline 4 & $138(100.0)$ & $0(0)$ & \\
\hline \multicolumn{4}{|l|}{ Weight (kg) } \\
\hline Median (IQR) & $57.0(18.8,65.8)$ & $60.0(53.0,72.0)$ & 0.001 \\
\hline \multicolumn{4}{|l|}{ ART regimen (\%) } \\
\hline Non-protease inhibitor-based & $119(86.2)$ & 264(91.4) & 0.104 \\
\hline Protease inhibitor-based & $19(13.8)$ & $25(8.6)$ & \\
\hline
\end{tabular}

\section{* Missing values}

TLC $t=$ Total Lymphocyte Count

a Proportion of patients adherent to ART in the ADC group; $12.3 \%(17 / 138)$

b Proportion of patients adherent to ART in the non-ADC group;65.6\%(187/285)

We found a significant association between adherence level and time to immunological recovery. The hazard of attaining immunological recovery when a patient had adherence level of $\geq 95 \%$ compared to one of lower adherence level was 2.2. The adherence level to ART in the ADC group was much lower than the non-ADC group. Similarly, the proportion of patients who achieved virological suppression in the ADC group was lower than the nonADC group. The non-adherence in the ADC group could have resulted from the pill burden as a result of the concomitant medications other than the drug-drug interactions from the rifampicin-based and ART regimens which has been reported else where [9]. During the intensive phase of the anti-tuberculosis treatment, patients were 


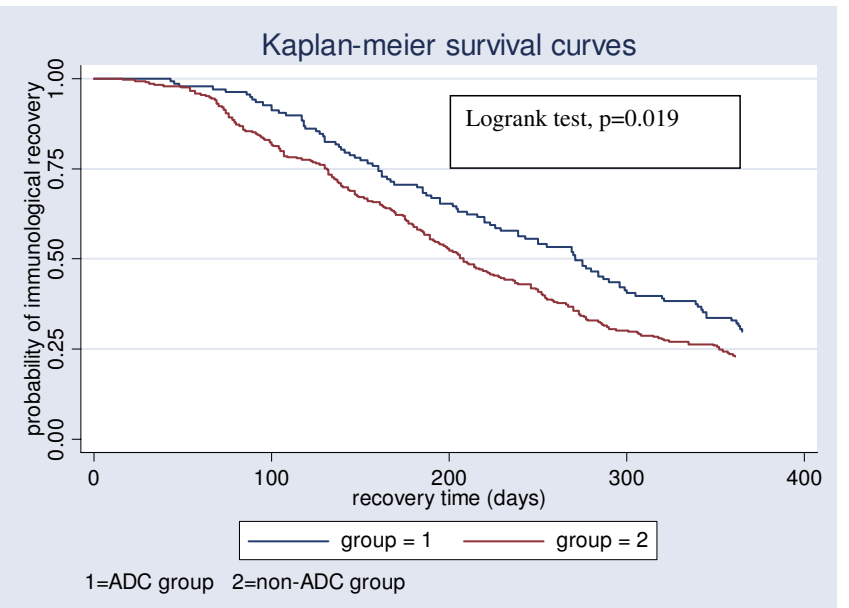

Figure 2

Kaplan-Meier survival curves comparing time to immunological recovery among 427 patients during ART initiation at JCRC during 2002-2006.

started on efavirence instead of niverapine-based regimens, although in some patients ART was deferred until the intensive phase was completed. Another reason for the non-adherence was that the patients were too ill to adhere to ART medications due to the concurrent co-morbidities which is a common feature in the sub-Saharan Africa [22]. Our adherence levels to attain immunological recovery are similar to what other studies have found. In a multicentre study in Africa $\geq 95 \%$ to ART was necessary to achieve viral suppression and increase in CD4 counts [23]. In another study in the USA, adherence of $\geq 95 \%$ to protease inhibitors was necessary to achieve a good immunological recovery [24]. During ART initiation, the majority of our patients $(89.7 \%)$ had been started on nonprotease ART regimens.

A baseline total lymphocyte count $\geq 1200$ cells $/ \mathrm{mm}^{3}$ was found to be associated with a short median time to immunological recovery. The hazard of attaining immunological recovery increased by 1.8 times when comparing a patient with a total lymphocyte count of $\geq 1200$ cells/ $\mathrm{mm}^{3}$ to one of a lower total lymphocyte count. Some studies have confirmed the significant association between a total lymphocyte count of $<1200$ cells $/ \mathrm{mm}^{3}$ and subsequent poor immunological recovery, disease progression or mortality $[25,26]$.

In our study, old age was not associated with median time to immunological recovery, although a significant association at bivariate analysis was observed. Later, this association between old age and time to immunological recovery disappeared after adjusting for other variables. Our findings are similar to those in a cohort of older participants in the USA ( $\geq 55$ years) where increasing age was associated with a slower and lower immunological recovery due to age-related decreases in thymopoiesis [27]. The 2 cohorts differed in their mean age. The mean age of the patients in our cohort was 40 years whereas for the cohort in the USA was 55 years.

We also found no effect of sex on median time to immunological recovery. Our findings are similar to other findings else where that show that there are no gender differences between males and females regarding response to ART [28]. On the contrary, one study of antiretroviral-naive patients found that women had a greater CD4 cell response than men, even after adjusting for baseline CD4 cell count and viral load. Pharmacokinetic differences may have resulted in women having higher antiretroviral drug levels, which led to more-profound virus suppression and resulted in a greater increase in CD4 cell count [15].

We recognize our study had the following limitations;

Our study design did not allow for the control of all possible confounders as it was retrospective cohort. We relied on measurements taken in the past and where a possible confounder was not measured we could not control for it. For example, we were not able to determine the effect of Body Mass Index (BMI) as height measurements were only available in about 35 patients. Although the baseline body weights were available, subsequent measurements during the follow-up visits were missing and only available in 40 patients. A baseline BMI of $<20.3 \mathrm{~kg} / \mathrm{m}^{2}$ for men and $<18.5 \mathrm{~kg} / \mathrm{m}^{2}$ for women is predictive of poor immunological recovery, increased morbidity and mortality $[29,30]$. We were also not able to determine the effect of payment for ART services as this information was not also available, although we found from the chart reviews that some patients were paying for ART drugs.

The time taken to attain 50 CD 4 cells/ $\mu$ l after ART initiation was estimated according nearest date of visit to JCRC outpatient clinic when the CD4 count was done. This estimation could have over or underestimated the true estimate. To minimize errors in estimation of time to attain $50 \mathrm{CD} 4$ cells/ $\mu \mathrm{l}$ both the principal investigator and data entrant independently calculated the time, and where differences arose an average was taken. Overall interobserver kappa statistic was 0.68 .

Another bias could have resulted from under diagnosis of ADCs because of lack of diagnostic equipments, a common finding in resource limited settings. It is surprising that some of the ADCs were not diagnosed during 20022006 when we reviewed records, whereas had been found to be prevalent by other study sites. For example in a nearby main referral hospital, $18 \%$ of hospitalized 
Table 3: Bivariate analysis of socio-demographic and clinical characteristics that affect time to immunological recovery among 427 patients initiated on ART at JCRC, during 2002-2006

\begin{tabular}{|c|c|c|c|}
\hline Variables & $\begin{array}{l}\text { Unadjusted } \\
\text { hazard ratio }\end{array}$ & $95 \% \mathrm{Cl}$ & p-value \\
\hline \multicolumn{4}{|l|}{ Sex } \\
\hline Male & 1.00 & & \\
\hline Female & 1.02 & $0.8 \mathrm{I}-\mathrm{I} .28$ & 0.879 \\
\hline \multicolumn{4}{|l|}{ Age (years) } \\
\hline$\leq 40$ & 1.00 & & \\
\hline$>40$ & 1.25 & $\mathrm{I} .0 \mathrm{I}-\mathrm{I} .56$ & 0.046 \\
\hline \multicolumn{4}{|l|}{ Group status } \\
\hline ADC & 1.00 & & \\
\hline Non-ADC & 1.33 & $1.05-1.69$ & 0.020 \\
\hline \multicolumn{4}{|l|}{ CD4 (cells/ $\mu \mathrm{l})$} \\
\hline$>200$ & 1.00 & & \\
\hline$\leq 200$ & 0.77 & $0.60-0.98$ & 0.034 \\
\hline \multicolumn{4}{|l|}{ Viral load (log I 0 copies/ml) } \\
\hline$<6.0$ & 1.00 & & \\
\hline$\geq 6.0$ & 0.93 & $0.88-0.98$ & 0.007 \\
\hline \multicolumn{4}{|l|}{ Hemoglobin (g/dl) } \\
\hline$\leq 10.0$ & 1.00 & & \\
\hline$>10.0$ & 0.87 & $0.64-1.19$ & 0.387 \\
\hline Prophylaxis & 1.00 & & \\
\hline Cotrimoxazole & 0.97 & $0.51-1.83$ & 0.926 \\
\hline Dapsone & 0.82 & $0.58-1.16$ & 0.274 \\
\hline Fluconazole & 0.97 & $0.72-1.30$ & 0.830 \\
\hline \multicolumn{4}{|l|}{ None } \\
\hline \multicolumn{4}{|l|}{ Adherence level (\%) } \\
\hline$<95$ & 1.00 & & \\
\hline$\geq 95$ & 2.31 & $1.84-2.90$ & 0.001 \\
\hline \multicolumn{4}{|l|}{ Weight (kg) } \\
\hline$\leq 60.0$ & 1.00 & & \\
\hline$>60.0$ & 0.81 & $0.64-1.01$ & 0.067 \\
\hline \multicolumn{4}{|l|}{ ART regimen } \\
\hline Non-protease inhibitor-based & 1.00 & & \\
\hline Protease inhibitor-based & 0.86 & $0.59-1.26$ & 0.446 \\
\hline \multicolumn{4}{|c|}{ Total lymphocyte count (cells $\left./ \mathrm{mm}^{3}\right) \times 10^{3}$} \\
\hline$<1.2$ & 1.00 & & \\
\hline$\geq 1.2$ & 1.55 & $1.04-2.30$ & 0.031 \\
\hline
\end{tabular}

patients presented with non-typhoid salmonella, as an ADC in blood stream [31]. We minimized under diagnosis of ADC by chart review to compare diagnosis of what was in data base whether conforms to what is in the charts. Another explanation could be that our facility was predominantly an out-patient setting.

Some of the immune responses after ART initiation were likely to have been evoked by immune reconstitution syndrome (IRS) and diagnosed as ADCs. This is an inflammatory response against infectious and non-infectious antigens and usually occurs within 12 weeks after ART initiation [32]. However, only less than 3\% of patients had ADCs within 12 weeks of ART initiation, thus ruling out the confounding effect of IRS.
We could also not explain a big loss to follow-up of patients who had enrolled for ART as it was inadequately documented. Of 609 who were eligible and enrolled for ART, 182 (29.9\%) could not come for second or subsequent review visits. We could explain the loss follow-up could have resulted from deaths due to profound immuno-suppression at ART initiation. Our findings may have overestimated individuals achieving immunological recovery, as those who died from an AIDS-defining disease shortly after starting ART were excluded from the analysis. It is also possible that these patients sought treatment in other treatment centers elsewhere. Since 2003, Uganda has benefited from roll-out program for ART services where more centers have been accredited to offer HIV services and treatment has been either subsided or 
Table 4: Multivariate analysis of factors that affect time to immunological recovery among 427 patients initiating ART at JCRC, during 2002-2006

\begin{tabular}{|c|c|c|c|}
\hline Variables & $\begin{array}{l}\text { Adjusted } \\
\text { Hazard ratio }\end{array}$ & $95 \% \mathrm{Cl}$ & p-value \\
\hline \multicolumn{4}{|l|}{ Group status } \\
\hline Non-ADC & 1.00 & & \\
\hline ADC & 1.31 & $1.03-1.28$ & 0.028 \\
\hline \multicolumn{4}{|l|}{ CD4(cells/ $\mu l)$} \\
\hline$>200$ & 1.00 & & \\
\hline$\leq 200$ & 0.52 & $0.37-0.77$ & 0.001 \\
\hline \multicolumn{4}{|c|}{ Viral load(copies log $10 / \mathrm{ml})$} \\
\hline$<6.0$ & 1.00 & & \\
\hline$\geq 6.0$ & 0.91 & $0.90-1.04$ & 0.806 \\
\hline \multicolumn{4}{|l|}{ Age(years) } \\
\hline$\leq 40$ & 1.00 & & \\
\hline$>40$ & 1.11 & $0.8 \mathrm{I}-1.67$ & 0.504 \\
\hline \multicolumn{4}{|l|}{ Sex } \\
\hline Male & 1.00 & & \\
\hline Female & 1.18 & $0.85-1.67$ & 0.334 \\
\hline \multicolumn{4}{|c|}{ Adherence level(\%) } \\
\hline$<95$ & 1.00 & & \\
\hline$\geq 95$ & 2.22 & $1.57-3.15$ & 0.001 \\
\hline \multicolumn{4}{|c|}{ Total lymphocyte count (cells $\left./ \mathrm{mm}^{3}\right) \times 10^{3}$} \\
\hline$<1200$ & 1.00 & & \\
\hline$\geq 1200$ & 1.84 & $1.22-2.78$ & 0.003 \\
\hline
\end{tabular}

become free. The loss to follow-up of $29.9 \%$ could have resulted into affecting the generalizability of the study findings. This was minimized by taking precautions to prevent under or over diagnose ADCs by chart review, and correct estimation of time to end points from baseline value by taking independent measurements. Secondly, the baseline characteristics of the patients who were lost to follow-up were similar to the patients who had a subsequent follow-up after the baseline visit (CD4 counts 131 vs 115 cells/ $\mu \mathrm{l} ; \mathrm{p}=0.640$ ). Lastly, findings of this study are strengthened by the relatively homogeneous study population receiving treatment at a single health facility using the national treatment protocols. Patients were all ART-naïve and received a standard triple-drug regimen.

\section{Conclusion}

We can draw the following conclusions from the study;

Patients with ADCs take longer to regain their CD4 counts due to the defect in immune system. This may prolong their risk to morbidity and mortality as a result of opportunistic infections. This paper provides a very strong argument for earlier ART initiation in a Ugandan setting. A key challenge is how to identify and initiate ART among patients with less advanced disease. Early Voluntary Counseling and Testing (VCT), the promotion of VCT within community settings so that people know their HIV sero-status and those who are HIV positive are encouraged so seek early health interventions is one option. Another option would be starting ART at above the threshold of 200 CD4 cells/ $\mu$ l. Recently, the Ugandan ART guidelines has recommended initiating ART at 250 and to 350 cells/ $\mu \mathrm{l}$ among pregnant women [3]. The third option would be active surveillance of among patients interfacing with the healthcare system. As previously suggested by Lawn SD et al [4], an obvious target population is those with tuberculosis (TB) and HIV-infected pregnant mothers identified in antenatal clinics (ANCs). These target populations represent a key opportunity for identifying many patients with both advanced and less-advanced immunodeficiency. For example, treatment of pregnant mothers at ANCs is likely not only to result in better outcomes but also to prevent vertical transmission of HIV. Thus, provision of facilities for HIV testing and CD4 cell count measurement at antenatal clinics warrants prioritization as access to ART is increased in low-income countries. Furthermore, although costly, provision of CD4 cell count 
measurements at voluntary counseling and testing facilities would also help identify other asymptomatic individuals with less-advanced disease who are eligible for ART.

\section{Competing interests}

The authors declare that they have no competing interests.

\section{Authors' contributions}

BKK: Study concept and design, data analysis, interpretation of the study findings and wrote-up the manuscript. SS, MP, BN, CK, EK: Assisted in the interpretation of study findings and the critical revision the manuscript. JK: assisted in data analysis, interpretation of study findings and the critical revision of the final manuscript. MO: Queried and extracted data from JCRC database. PM: assisted in critical revision and the final approval of manuscript. FS: Assisted in the study concept and design, interpretation of the study findings and the critical revision of the manuscript.

\section{Acknowledgements}

We thank all the staff in at JCRC who supported our work. Most importantly, we thank the patients. This study was supported in part by grant A1025879-17S2 from the National Institutes of Health, Bethesda, USA.

\section{References}

I. WHO: Antiretroviral therapy for HIV infection in adults and adolescents. recomendations for a public health approach. 2006 [http://www.who.int/hiv/pub/guidelines/artadultguidelines.pdf].

2. Amolo-Okero F, Aceng E, Madraa E, Namagala E, Serutoke J: Scaling up antiretroviral Therapy: Experience in Uganda. 2003 [http:I /www.emro.who.int/aiecf/web46.pdf]. WHO

3. Uganda: National Antiretroviral Treatment Guidelines for Adults, Adolescents and Children. Ministry of Health; 2008.

4. Lawn S, Wood R: How can earlier entry of patients into antiretroviral programs in low-income countries be promoted? Clin Infect Dis 2006, 42(43I-432): [http://www.jour nals.uchicago.edu/doi/abs/10.1086/ 499527?url ver $=Z 39.82003 \&$ rfr id $=$ ori:rid:cross ref.org\&rfr dat $=c r$ pub\%3dncbi.nlm.nih.gov].

5. Lederman HM, Williams PL, Wu JW, Evans TG, Cohn SG, McCutchan J: Incomplete immune reconstitution after initiation of highly active antiretroviral therapy in human immunodeficiency virus-infected patients with severe CD4+ cell depletion. J Infect Dis 2003, 188:1794-1803.

6. Lawn S, Bekker L, Robin R: How effectively does HAART restore immune responses to Mycobacterium tuberculosis? AIDS 2005, 19:1113-1124.

7. Weidle PJ, Malamba S, Mwebaze R, Sozi C, Rukundo G, Downing R, Hanson D, Ochola D, Mugyenyi P, Mermin J, Samb B, Lackritz E: Assessment of a pilot antiretroviral drug therapy programme in Uganda: patients' response, survival, and drug resistance. Lancet 2006, 360(9326):34-40.

8. WHO: World Health Organization Clinical Staging System. 1993.

9. Moreno S, Hernández B, Dronda F: Antiretroviral therapy in AIDS patients with tuberculosis. AIDS Rev 2006, 8(3): I I5-I24.

10. Ungsedhapand C, Srasuebkul P, Cardiello P, Ruxrungtham K, Ratanasuwan $\mathrm{W}$, Kroon ED, Tongtalung $\mathrm{M}$, Juengprasert $\mathrm{N}$, Ubolyam $\mathrm{S}$, Siangphoe U, Emery S, Lange JM, Cooper DA, Phanuphak P, HIV-NAT 002 and HIV-NAT 003 Study Team: Three-year durability of dual-nucleoside versus triple-nucleoside therapy in a Thai population with HIV infection. J Acquir Immune Defic Syndr 2004, 36(2):693-70I.

II. Yamashita TE, Phair JP, Muñoz A, Margolick JB, Detels R, O'Brien SJ, Mellors JW, Wolinsky SM, Jacobson LP: Immunologic and viro- logic response to highly active antiretroviral therapy in the Multicenter AIDS Cohort Study. AIDS 200I, I 5(6):735-746.

12. Le Moing V, Thiébaut R, Chêne G, Sobel A, Massip P, Collin F, Meyohas M, Al Kaïed F, Leport C, F R: Long-term evolution of CD4 count in patients with a plasma HIV RNA persistently $<500$ copies $/ \mathrm{mL}$ during treatment with antiretroviral drugs. HIV Med 2007, 8(3): 156-163.

13. Lima VD, Harrigan R, Murray M, Moore DM, Wood E, Hogg RS, Montaner JS: Differential impact of adherence on long-term treatment response among naive HIV-infected individuals. AIDS 2008, 22(I7):237|-2380.

14. Mahesh KP, Machin D: Survival analysis. A practical approach John Wiley \& Sons; 1996

15. Giordano TP, Wright JA, Hasan MQ, White AC Jr, Graviss EA, Visnegarwala F: Do Sex and Race/Ethnicity Influence CD4 Cell Response in Patients Who Achieve Virologic Suppression during Antiretroviral Therapy? Clin Infect Dis 2003, 37(3):433-437.

16. Lawn SD, Myer L, Bakker LG, Wood R: CD4 cell count recovery among HIV-infected patients with very advanced immunodeficiency commencing antiretroviral treatment in subSaharan Africa. BMC Infect Dis 2006, 6:59.

17. Barlett JG, Gallant J: Medical management of HIV infection John Hopkins Medicine Health Publishing Group; 2007.

18. Lawn SD, Butera ST, Folks TM: Contribution of Immune Activation to the Pathogenesis and Transmission of Human Immunodeficiency Virus Type I Infection. Clin Microbiol Reviews 200I, I4(4):753-777.

19. Battegay M, Nuesch R, Hirschel B, Kauffman R: Immunological recovery and antiretroviral therapy in HIV infection. Lancet Infect Dis 2006, 6(5):280-287.

20. Anastos K, Kalish LA, Hessol N, Weiser B, Melnick S, Burns D, Delapenha R, DeHovitz J, Cohen M, Meyer W, Bremer J, Kovacs A: The relative value of CD4 cell count and quantitative HIV-I RNA in predicting survival in HIV-I-infected women: results of the women's interagency HIV study. AIDS 2000, I3(13): 17 I7-I726.

21. Coakley EP, Samore MH, Gillis JM, Hughes MD, Hammer SM: The values of quantitative serum HIV-I RNA levels and CD4 cell counts for predicting survival time among HIV-positive individuals with CD4 counts of $<$ or $=50 \times$ I0(6) cells/l. AIDS 2000, 14(9): I I 47-III53.

22. Holmes CB, Losina E, Walensky RP, Yazdanpanah Y, Freedberg KA Review of human immunodeficiency virus type I-related opportunistic infections in sub-Saharan Africa. Clin Infect Dis 2003, 36(5):652-662.

23. Muyingo SK, Walker AS, Reid A, Munderi P, Gibb DM, Ssali F, Levin J, Katabira E, Gilks C, Todd J: Patterns of individual and population-level adherence to antiretroviral therapy and risk factors for poor adherence in the first year of the DART trial in Uganda and Zimbabwe. J Acquir Immune Defic Syndr 2008, 48(4):468-475.

24. Paterson DL, Swindells S, Mohr J, Brester M, Vergis EN, Squier C, Wagener MM, Singh N: Adherence to protease inhibitor therapy and outcomes in patients with HIV infection. Ann Intern Med 2000, I33(I):2I-30.

25. Lau B, Gange SJ, Phair JP, Riddler SA, Detels R, Margolick JB: Use of total lymphocyte count and hemoglobin concentration for monitoring progression of HIV infection. Jaids-Journal of Acquired Immune Deficiency Syndromes 2005, 39(5620-625 [http://jour nals.Iww.com/jaids/Fulltext/2005/08/50/ Use of Total Lymphocyte Count and Hemoglobin. 18.aspx]

26. Gange SJ, Lau B, Phair J, Riddler SA, Detels R, Margolick JB: Rapid declines in total lymphocyte count and hemoglobin in HIV infection begin at CD4 lymphocyte counts that justify antiretroviral therapy. AIDS 2003, I7(I): II9-121.

27. Hynes B, Markert M, Sempowski GD, Patel DD, Hale LP: The role of thymus in immune reconstitution in aging, Bone marrow transplantation, and HIV-I infection. Annul Rev Immunol 2000, I8:529-560.

28. Patterson K, Napravnik S, Eron J, Keruly J, Moore R: Effects of Age and Sex on Immunological and Virological Responses to Initial Highly Active Antiretroviral Therapy. HIV Med 2007, 8(6):406-410.

29. Castetbon K, Anglaret XTS, Chene G, Ouassa T, Attia A, N'DriYoman T, Malvy D, Salamon R, Dabis F: Prognostic value of crosssectional anthropometric indices on short-term risk of mor- 
tality in human immunodeficiency virus-infected adultsin Abidjan, Cote d'Ivoire. American Journal of Epidemiology 200I, I 54(I):75-84.

30. Thiébaut R, Malvy D, Marimoutou C, Davis F: Anthropometric indices as predictors of survival in AIDS adults. Aquitane cohort, France, 1985-1997. Eur Journ of Epidemiol 2000, 16(7):633-639.

31. Ssali FN, Kamya MR, Wabwire-Mangen F, Kasasa S, Joloba M, Williams $D$, Mugerwa RD, Ellner J], Johnson JL: A prospective study of community-acquired bloodstream infections among febrile adults admitted to Mulago Hospital in Kampala, Uganda. J Acquir Immune Defic Syndr Hum Retrovirol 1998, 19(5):484-489.

32. Kumarasamy N, Chaguturu S, Mayer KH, Solomon S, Yepthomi HT, Balakrishnan P, Flanigan TP: Incidence of immune reconstitution syndrome in HIV/tuberculosis-coinfected patients after initiation of generic antiretroviral therapy in India. J Acquir Immune Defic Syndr 2004, 37(5): I574-I576.

Publish with Bio Med Central and every scientist can read your work free of charge

"BioMed Central will be the most significant development for disseminating the results of biomedical research in our lifetime. "

Sir Paul Nurse, Cancer Research UK

Your research papers will be:

- available free of charge to the entire biomedical community

- peer reviewed and published immediately upon acceptance

- cited in PubMed and archived on PubMed Central

- yours - you keep the copyright

Submit your manuscript here:

http://www.biomedcentral.com/info/publishing_adv.asp
BiolMedcentral 